\title{
Personal Attributes and Motivation of Female Micro-Entrepreneurs in Ghana: A Case of Fishmongers in Central Region
}

\author{
Christina Boateng \\ Department of Vocational Technical Education and Training \\ University of Cape Coast, Cape Coast, Ghana
}

Tel: 233-262-838-004Ｅ-mail: christina.boateng@ucc.edu.gh

Received: August 14, 2013 Accepted: August 30, 2013

doi:10.5296/ber.v4i1.4114 URL: http://dx.doi.org/10.5296/ber.v4i1.4114

\begin{abstract}
The research was carried out among women micro entrepreneurs who engage in fish mongering, one of the well known entrepreneurial activities of women in Ghana. The purpose of the study was to explore the personal and business characteristics as well as the motives behind the women's entrepreneurial activities to provide a baseline data based on which policy and support programs could be devised to aid women's economic development. The study revealed that majority of women fishmongers had an average age of 42 years old, were married with large families; had no formal education but had acquired training for their businesses through apprenticeship. The study also revealed that majority of the women had received start -up capital from family members as gift and have been able to build up sizable businesses through which they are able to employ other people, cater for their families and reinvest. They do have a positive attitude for their businesses and therefore employ several strategies to maximize their profits. The study further identified family circumstances and economic pressure, economic independence, and need for social recognition as the motives for their entrepreneurial activities. The study therefore concludes that the women's participation and performance in entrepreneurial activities are stimulated and shaped by socio-cultural, and socio- economic factors. As such, any intervention programs and policies for the entrepreneurial development of these particular women should take into consideration their identified characteristics and the unique impart they have on women's entrepreneurial behaviors.
\end{abstract}

Keywords: Entrepreneurship, Micro entrepreneurs, Women entrepreneurs, Micro-enterprise, Fishmongers, Fish mongering 


\section{Introduction}

Entrepreneurship is a major catalyst for economic growth, productivity, and development in both industrialized and developing countries. History has shown that entrepreneurs establish new businesses that create employment and provide services and products to increase the wealth of their local and national economies. Nevertheless, a significant number of enterprises were owned by men; and the idea and practice of women entrepreneurship is a recent phenomenon. The International Labor Organization, ILO (2006) reported that women entrepreneurship and women owned and run organizations was the development of the 1980s when recognition that women's economic empowerment is one avenue for reducing poverty and spurring economic growth and development occurred.

Female entrepreneurship and women entrepreneurs have since the 1980s been on the rise. There are a number of women entrepreneurs in business now. However, studies have shown that most of them are found in Small and Medium Enterprises (Global Entrepreneurship Monitor (GEM), 2003). The case of Africa is no different where women play a more limited role as owners and managers in the formal sector (Acs, 2007). In sub- Saharan African economies, it is reported that women are highly represented in the micro and small enterprises sub-sector where they engage in small income generating self-employment in agriculture and non-agricultural activities. About $84 \%$ of women are informally employed, as compared to $63 \%$ of men in these countries (Spring, 2009). In Ghana, in particular, women are holding their own in entrepreneurship and economic participation. They constitute about half of the entire labor force operating mostly in the informal economy where they outnumber men, and are particularly involved in various micro-enterprises and retail trade and are contributing to national output growth even though this is often not measured (International Financial Corporation, 2007).

With the realization of the importance of Ghanaian women's involvement in the micro enterprise sector and their contribution to the growth of the economy, government, donor agencies, non-governmental agencies and other women organization have put in place programs and projects to help women realize their full potential. For example in 2012, Hunger Project - Ghana through its Microfinance Program disbursed over \$300,000 to women micro entrepreneurs in the Eastern Region of Ghana (The Hunger Project - Ghana, 2013). In 2007, the (IFC) reported that in Ghana there is limited information and empirical evidence on the informal sector and those subsectors of the economy in which women predominate. However, without information, there cannot be better focused, more effective or relevant policy and program development that will enable women take advantage of entrepreneurial opportunities to expand and achieve their fullest economic potential. This study was directed towards finding out about the personal characteristics and motivation of the women who operate as micro entrepreneurs in the informal sector of the Ghanaian economy and how these characteristics affect their entrepreneurial activities and behaviors. It is expected that the result of the study will inform the design and development of appropriate assistance programs and policies geared towards enhancing women's entrepreneurial activities and economic empowerment. 


\section{Women in Entrepreneurship}

There is empirical evidence suggesting that entrepreneurship generally, and women entrepreneurship specifically, contributes in various ways to economic development and poverty reduction of nations as they help to reduce unemployment and create wealth. This has raised the profile and the importance of entrepreneurship especially in developing countries. In spite of this, entrepreneurship has been described as a complex and multifaceted phenomenon affected by culture and social traditions (Minniti and Arenius, 2003). This means that cultural and social factors play a large role in determining who within a society becomes an entrepreneur. For example, social conditions in some societies inhibit women from starting their own businesses.

Minniti and Arenius (2003) also reported that women entrepreneurship is a cross-cultural phenomenon with culture specific aspects including two different components. The first component is that there are variables (i.e. age, education, perceived skills, and social network) that influence entrepreneurial behavior across countries and across gender. Thus, there are universal variables, which affect both sexes but not necessarily in the same way or with the same intensity. This implies that women and men are influenced by many of the same variables when making entrepreneurial decisions. However, the fact that male entrepreneurship rates are systematically and significantly higher than female entrepreneurship rates all over the world indicates an unevenness of universal factors across the sexes that may cause men and women to behave differently with respect to entrepreneurship.

There have been several studies supporting this view. OECD (1998) reported that women entrepreneurs are overrepresented in the retail- and service sectors, in particular, in personal services while male entrepreneurs are overrepresented in manufacturing, wholesale trade and financial services. Again, Van Uxem and Bais (1996) had found that even within sectors, women entrepreneurs are often found in supporting jobs or occupations. Moreover, they found that women value their own entrepreneurial characteristics lower than men although the difference with respect to entrepreneurial characteristics was rather small. Thus men put a higher value on perseverance and risk and a lower value on autonomy and change than women do. This is the case especially with regard to taking risk, industry knowledge and technological knowledge. This lack of confidence of women entrepreneurs in their own entrepreneurial capabilities has been attributed to a relatively negative self-perception, which has resulted largely from social and cultural factors (Hofstedein 1991). Also, in 2001, Verheul and Thurik reported that men and women entrepreneurs are very prevalent in two distinct sectors: the formal or traditional mainstream sector, and the informal or marginalized sector respectively. They further concluded that men and women may differ with respect to the sector they work in, their background and experience, the size of their enterprises, etc. because their societal opportunities are unevenly distributed or because of differences in heir upbringing.

Differences in the entrepreneurship behavior of men and women have also been observed on the bases of how much time they devote to entrepreneurial activities. Men have been reported to work more often on a full-time basis when compared to women (OECD, 1998). More than half of enterprising women carry out other activities besides running their own businesses, 
such as taking care of families and doing other household activities (Stigter, 1999) Thus, women entrepreneurs are said to have "double assignments"; i.e. they are running enterprises and households at the same time. These "double assignments" may limit the time women entrepreneurs spend on their businesses, thus, affecting their output as entrepreneurs.

The second component of entrepreneurial inclinations outline by Minniti and Arenius (2003) is the idea that entrepreneurial behavior is country - specific. From a comparative study of female Total Entrepreneurial Activity (TEA) index conducted in 37 countries in 2002, participation of women in entrepreneurship varies significantly across the 37 countries, ranging from 0.6 percent $(6$ per 1,000$)$ in Japan to 18.5 percent $(185$ per 1,000$)$ in Thailand (Reynolds, Hay, Camp, and Autio, 2002). It is country-specific characteristics that determine the differences in prevalence rates for women entrepreneurship across countries.

\subsection{Profile of African Women Entrepreneurs}

There have been several studies associating African women business owners with informal and part-time operations. African women have not been considered "real" entrepreneurs but "pushed into" business as a "no choice" option for escaping from poverty (Zewde\& Associates, 2002). They have therefore been referred to as "lifestyle" entrepreneurs (OECD, 2004; Hall, 2003).This has consequently become the de facto profile of women entrepreneurs in Africa. Secondary research in three countries of Ethiopia, Tanzania andZambia, conducted by Richardson, Howarth\& Finnegan in 2004 identified African women entrepreneurs as follows;

a) Women who are poor, have few if any of their own assets, and have limited means of accessing such resources from others.

b) Women who have low levels of formal education at best, but are more likely to have had no formal education, to be illiterate and in general have limited human assets.

c) Women who have limited or no experience of formal employment and business.

d) Women who have limited business and managerial experience prior to start-up.

e) Women who have limited networks especially business-related networks.

f) Women who are not highly or positively motivated towards business ownership.

Whilst these characteristics define women entrepreneurs in Africa, there is the need to examine the prevalence of this profile in the face of the assertion that women entrepreneurship is affected by socio-cultural factors ; so that a better understanding of women entrepreneurship in specific countries could be developed.

\subsection{Why Women Start Businesses}

Some researches have labeled women as having inappropriate attitudes towards business (ODEC, 2002). However, the field research conducted in Ethiopia, Tanzania and Zambia revealed that most of the women are very committed to their businesses, and have clear plans for further developing their businesses (Richardson, Howarth and Finnegan, 2004). In all three countries, the majority of the women entrepreneurs interviewed had been the sole or primary drivers for starting their businesses. In terms of motivation for start-up, the women entrepreneurs reported having a range of reasons for choosing to start their own businesses. The study revealed the desire to be self-employed and independent and the need for income as 
the main drivers for Ethiopian and Tanzanian women. In Zambia, there was greater emphasis on income generation. Another study by Jalbert (2000) revealed that women's motivations for starting businesses are related to their need to be independent, achieve job satisfaction, attain personal accomplishment and fulfillment, and be creative and economically self-sufficient. Again, Moore and Buttner (1997) had earlier suggested that women started their own businesses from a desire for self-determination and for career challenge, and that they expect the corresponding respect, recognition, and self-esteem that both self-determination and challenge provide.

The preceding presentation confirms the need to construct a very comprehensive profile of women entrepreneurs by any agency interested in providing an environment in which women entrepreneurship is to flourish.

\section{Methodology}

This study employed a case study approach to explore, identify and generate as much knowledge as possible about the population as a social group. The population was made up of fishmongers from the Central Region of Ghana. One Hundred and twenty women were purposively selected from ten villages and communities where fishing expedition is done commercially and fish mongering is more brisk and perennial. The criterion for inclusion in the sample was business ownership. The sampling was done with the help and assistance of the Community Development Units in the fishing communities. Data was collected by a team of four using in-depth face-to- face interview method over a period of two months from mid -January to mid- March 2013. The interview schedule constructed for the data collection had three main sections. The first section had items to gather information on the socio-economic characteristics of the entrepreneurs, the second section had items on their business characteristics and the third had items covering the motive behind their entrepreneurial behavior. The data collected was analyzed using Microsoft Excel and interpreted using descriptive statistics such as percentages and frequencies. Conclusions were drawn based on the results.

\section{Results and Discussion}

\subsection{Demographic Characteristics}

The women entrepreneurs interviewed came from varying age groups. Their ages ranged between 29 and 79 years with an average age of 42 years. This does not suggest that younger women are not involved in fishing processing and distribution. It was realized that younger women are very much interested in fish mongering and are involved as apprentices or helps in the business operations of their mothers or other female relatives and would establish their own businesses when they get the resources. Considering the average age of the respondents and the fact that many of them had been involved in the business as helps and apprentices before owning their own operations suggest they have had enough time to acquire some entrepreneurial skills and business acumen they need in operating their own businesses.

The study established that majority of the respondents (90\%) were married and had large families. The $10 \%$ who had no husbands were made up of widows and divorcees who 
considered themselves too old to re-marry. There are two main reasons for the high representation of married women among the respondents. The first reason is that they live in a society where high status is attached to marriage and having children. Again, by the socialization process of women in this society, they are expected to adopt and conform to the socio-cultural systems and therefore tend to be married and have children. A second reason that explains the finding is that the women tend to marry hoping that their husbands will support them in the upbringing and upkeep of their children, or hoping that through their husbands, they can get access to resources and the right socio-economic linkages that could enable them make a viable career as fishmongers.

The implication of their marital and parental on their businesses is that they have to combine their roles as business owners with those as mothers and wives, and this can affect their business operations. For example, this may restrict their scale of operation since they have to spend time catering for their families.

The women in the study had an average of seven children. This exceeds the national average number of children per woman in Ghana, which was reported as 4.17(Ghana Statistical Services, 2012). In addition to their own children, all the women interviewed lived with and catered for other people ( dependents) within their households. These dependents included grandchildren, younger siblings, nieces, nephew, in-laws, house helps as well as parents. The dependents and the biological children al, shared the same house - keeping arrangement and are catered for as one unit by the entrepreneur. They may in one way or the other be involved in the business but are not paid wages. In return, they are dependent on the entrepreneur for their livelihood. The study also showed that the number of dependents they support ranges from 1-18 persons with a mean range of 7-10 people. The study also showed that about $77 \%$ of the entrepreneurs were the sole financial supporters for the members of their households. The other $23 \%$ of the entrepreneurs receive assistance from other members of the family such as husbands and older children especially sons to take care of the household. The financial responsibilities of the entrepreneurs enumerated included feeding, clothing, housing and utility, medical bills and school fees.

The large number of children and other dependents has some repercussions on the businesses run by the women. On one hand, the fact that the women contributed immensely to the household expenditure suggest that with the large family size, much of their income from their businesses is used to cater for the needs of their households rather than for reinvestment. They also have to spend time and energy fulfilling their reproductive roles. This may constrain their finances, time and mobility. On the other hand, the children and other family members provide practical support for the business. In many cases, large family size means large labor force for the women and thus a large scale of operation and turn over. Therefore, large family sizes are social assets and valuable resources for the entrepreneurial activities of the women but could also affect the growth of their businesses.

\subsection{Human Capital}

Lack of formal education is often quoted as a factor limiting the development of women as entrepreneurs and contributing to their lack of access to resources. The study found that $89 \%$ of 
the women had no formal education. The $11 \%$ who had formal education were made up of $4 \%$ who had completed primary school and $7 \%$ who had up to middle school level (elementary school) education. This is far lower than the national literacy rate of $65 \%$ among females in Ghana. However, all of them have had full time apprenticeship training in the business. The women had explained that their parents had considered it very important for daughters to understudy their mothers and other female relatives in their vocations rather than spending years in the formal school system trying to acquire skills for work. One could think of one reason why fisher folks keep their daughters out of formal schooling. It is their way of ensuring that their indigenous system of skills transmission from generation to generation apprenticeship- does not loose grounds. This is because it is their belief that when girls participate in formal education, they spend more time in school and less time working with their mothers in their businesses, which inevitably disrupt the system of transmission of skills from mothers to daughters. Furthermore, keeping girls out of formal schooling is their way of ensuring that they stay and work with their mothers as fishmongers when they grow up because their knowledge and experience is restricted to that business alone. This confirms an earlier finding by Coquery-Vidrovitch (1997) that uneducated daughters often have limited job opportunities options; and are restricted to stay in the same businesses as their mothers.

In spite of the benefit of full-time apprenticeship, which is essential for self-employment, it was observed that lack of formal education might pose a problem to the operation of the women as entrepreneurs. For example, it was found out that the women did not keep any written records of their business operations and transactions mostly because they cannot write. Again, they do not use any modern instruments such as calculators or weighing scales. They tend to do all calculations mentally. This is usually not possible especially where large sums of money or quantities of fish are involved. It was not surprising that some respondents intimated that they do not know how much money is involved in their businesses or what their turnovers were. The implication of this status on the women as entrepreneurs is that they would have to stay within a certain turnover where they could keep every bit of their transaction in their memory, something that affects the growth and expansion of their businesses.

The research also dealt with the occupational history of the women. It was found out that $67 \%$ of them had never engaged in any other type of occupation before. The $33 \%$ who had tried other occupations before were actually involved in other entrepreneurial activities. Such activities included petty trading, baking, sale of foodstuff, sale of firewood, sale of cooked food and preparation of oil. The research further revealed that out of the 33\%, only $8 \%$ were still operating the other businesses together with fish mongering. The rest had stopped and were solely in fish processing for various reasons. Some of the reasons they enumerated were: their perception that fish mongering was more lucrative than any other business in the study area; all other businesses are dependent on the prospects of fishing in the study area; the seasonal demand for the wares of other businesses and relocation into the study area where fish mongering is prevalent. Those who still combine fish mongering with other businesses sell cooked food, foodstuff and firewood. They added that they maintain them as secondary or subsidiary to fish mongering. 


\subsection{Business Characteristics}

Issues such as how women start and operate their enterprises, sources of their start -up capital, how and the extent of capital accumulation, profit, investment behavior and others need to be considered if women operating micro-enterprises are to be considered as entrepreneurs so that aid programs to owner - managers of firms could be extended to cover them.

\subsubsection{Source and Size of Start- Up Capital}

Surveys that have been carried out among women micro entrepreneurs demonstrate that they tap several sources of start-up capital. This study established that the fishmongers generated their start-up capital from varied sources with gifts from mothers and grandmothers as the most popular. Majority of them $(61 \%)$ received their start-up capital as gift from their mothers and grandmothers as gifts. They intimated that they had worked as apprentices with their mothers and grandmothers when they were young without being paid. As they approached adulthood, the mothers and grandmothers would save some amount of money at the end of every fishing season towards building up an initial capital for the daughters and granddaughters. It was found out that if a young woman worked faithfully until this stage, the mother becomes obliged to provide her with initial capital to start and operate her own business. Apart from mothers and grandmothers, a smaller number of the women (10\%) also obtained start-up capital from other relatives such as aunts, in-laws, husbands and brothers.

The study also revealed that a good number of the women (29\%) had started their businesses without any capital. It was found out that it was common practice for the fishing vessels to operate continuously for three to four months before the crewmembers take stock of their operation. It is at this time that financial accounts are rendered to the crew and the owner of the vessel; and any remuneration made to the crew. Therefore, within this period, the fishmongers can buy the fish on credit, process, sell and reinvest the money until it is time for stock to be taken. The women are then served notices to settle their debts. The problem the women who started without capital encountered according to them was that they mostly had to buy the fish at a price higher than those who buy with cash.

None of the women in the study had started their business with a loan from either relatives or institutional bank. Even though some of the women admitted having benefitted from institutional credit, they had enjoyed that facility only after the start-up period.

There were varying responses as to the size of their initial capital. The most experienced fishmonger interviewed (over forty years as a fishmonger) started her business with an initial amount equivalent to about \$0.10 US while the least experienced (two years as a fishmonger) started with an amount equivalent to $\$ 100.00$ US. The women mentioned that even though the modest amount of initial capital sometimes affected their scale of operation and turnover at the onset of their operation, it does not restrict their success in the business.

\subsubsection{Employment Creation and Remuneration}

All the women said they employed other people to help with the business. They use both family and hired labor. None of them relied on communal labor. The study revealed labor could be 
engaged either temporary or permanently; temporary labor, mostly hired, is used to carrying the fish from the landing beaches to the processing sheds for processing and for loading processed fish unto trucks bound for the market. Permanent labor however, is used for the actual processing of the fish and for marketing. This could be hired or family labor. The women studied employed between four and twenty persons depending on the size of their operation. This means that the women's business activities creates gainful employment for other people and contributes to the economic growth and development of their communities.

The mode of remuneration as gathered by the study depends on whether the employee is permanent or temporary. Temporary employees, mainly males, are paid wages on daily bases or on completion of a contract job. For permanent employees, who are mostly females, it again depends on whether the person provides family or hired labor. Remuneration for family labor is based on the profit or loss sharing system. In this system, what the employee receives is dependent on how much profit the employer makes. That is, the employer, usually a female relative provides the financial needs of the employee depending on how much they earn from the business until the employee reaches adulthood and ready to be independent. At this stage the employer now fulfills her obligation of providing her with "eguatsir" (start -up capital) to start her own business. Remuneration for hired labor on the other hand is fixed through negotiation between the employer and the employee before the start of work. However, it generally consist of pieces of cloths, head gears, cooking utensils, toiletries, sandals and an amount of money; and its payable on a yearly basis.

\subsubsection{Scale of Turnover and Profits}

The information gathered from the study could not be used to estimate how much profit the women made for the following reasons:

- The women do not keep written records of their business transactions

- They keep their personal accounts and business account together

- They do not account for the portion of income from the business that is spent on meeting their financial needs and the needs of their families

- They do not cost the large quantities of fish that is used off their stock for home consumption throughout the year.

- Some of the women were hesitant discussing finances and financial aspect of their business.

However, there was no doubt that that women made profit from their businesses considering the extent of growth and investment they have made and their declaration that they depend solely on their business to satisfy all their financial obligations. They shared that one can achieve great turnover and a good profit margin by applying the following strategies:

- Processing the fish before disposing of it rather selling it fresh to other women

- Smoking the fish very dry and storing it till the lean season( March - May) when prices are at their peak

- Buying and storing large quantities of fish during the bumper season (JuneOctober/September). 
- Sending the processed fish to the inland market centers for sale

- Establishing good social networks that help in getting access to the right to buy fish from canoes or crews and short- term credit sales.

- Offering short- term loans to fishing crews and negotiating to receive payment in the form of fish until the loan is repaid.

\subsubsection{Business Growth, Expansion and Re-Investments}

All the women had been able to increase the size of their capital and their operation since its inception. The women who started with gift money had added to their initial capital and those who had started on credit had managed to build up a sizable working capital. As at the beginning of the 2012 bumper season, $53 \%$ of the women had working capital ranging from GHS 200.00 to GHS 4,000.00 (\$100. 00 - \$2000. 00 US). The study revealed that it was common practice for fishmongers to allocate a portion of their yearly "profit" for re-investment. The researcher saw the "profit" as described by the women as the extra money on their circulating capital at the time of taking stock of their business, which usually occur during the lean season. This is irrespective of how much of their income has been spent on the financial needs of themselves and their families. Aside of operating capital, the women had also invested in ovens, smokers, trays, enamel head pans and basins, firewood, processing shed, processed fish and storage baskets and other structures.

The study further showed that fishmongers who are more successful had come to penetrate other segments of the fishing industry as a means of expanding their operations. Information gathered showed that about $15 \%$ of the respondents owned fishing boats, canoes and nets. By so doing they assure themselves of a steady supply of fresh fish all year round. Again $22 \%$ of the respondent had sales representatives and agents in the major market centers of the country who receive and distribute processed fish on their behalf for commission, while they concentrate on the actual processing of the fish. There were also respondents who had purchased trucks used in travelling to other fishing towns to purchase fresh fish for processing and to transport processed fish to the markets. These suggest that the micro entrepreneurs are able to broaden their range of operations. They attributed the growth to the business itself, thus, they had acquired all that with money from the fish mongering business.

The study also showed that after the women had accumulated sufficient capital, they would normally withdraw a portion of their earnings from the business and invest elsewhere. The study showed that $20 \%$ of the respondents had put up completed houses out of their earnings from their fish processing business and $37 \%$ have uncompleted houses. The respondents said they see shelter as a natural need for themselves and their families. At the same time, the houses are status symbol in their communities. Apart from that, it was observed that the houses served as the workshops for their businesses. It is in these same houses that they had built ovens, smokers and storage facilities for their operations and it is from here that they organize their employees to do the work of washing, smoking, packaging, storing, and distributing their products.

It was realized that there had been a substantial increase in the value of their businesses considering the size of their start-up capital. The revelation the women have a system in place 
to plough back profit means they have a positive attitude towards the growth of their business. However, it was obvious that the amount of money the women allocate for investment in the business is highly dependent on the financial obligations of the women towards their families. This implies that more money is invested in the business if financial obligations of the women towards her family are lower and vice versa.

\subsection{Motivating Factors}

The study identified four main motivational factors reasons for the women's involvement in fish mongering business. About $65 \%$ of the respondents were motivated by family circumstances and economic pressures to engage in fish mongering as a business. They shared that their children had been the driving force behind their businesses. They have to work to be able to meet the financial needs of the families. They had participated as apprentices in fish mongering when they were growing up. This was part of their upbringing and general preparation for adulthood and motherhood. Through this, they had acquired the technical and business skills, which they had readily put into practice when it came time for them to fulfill their social expectation of contributing to their households' expenditure.

Another $20 \%$ of the women had started their businesses because they wanted to be economically independent and not be a financial burden on other people. They said even though they had started by working with relatives, it became obvious as they grew up that they could not depend on these relatives for everything they needed. They therefore initiated their own businesses to be able to meet their financial needs. They see their businesses as a source of financial security and as a means by which they can establish themselves in the society and earn the opportunity to manage their own affairs. They therefore attach very high value to it.

Additional $11.6 \%$ of the women explained they had entered the business to improve their socio- economic status in their societies. They explained that fish mongering is one of the lucrative businesses in their communities. All other businesses were dependent on the fishing industry so the women who owned and operated businesses within this industry usually are able to earn higher income than women in other trades. Therefore, fishmongers have a higher social class, and many people went to them for advice and assistance.

A smaller percentage ( $4.4 \%)$ of the respondents had taken to the business due to certain changes that had occurred in their lives. These life-changing events were enumerated as divorce, death of relatives and relocation into a fishing community. They mentioned that it was the easiest business one could do if you had no capital to start a business, because, one could buy the fresh fish from fishermen on credit.

In fact, the above confirms the finding s by Burke A.E., Fitzroy F.R., Nolan M.A., (2002); Minniti (2003) that women tend to be more sensitive to a variety of non-monetary incentives in their choice to start one business or the other and their choices are often linked to necessity or to time and

location flexibility; for example, to the type of independence that can accommodate family needs and child rearing. 


\section{Conclusion}

The socio-economic characteristics such as age, level of education, marital status, number of children and dependants stimulate and shape the involvement and performance of women in fish mongering as a business. The way they organize to start, and operate their businesses, how they accumulate capital, their investment behavior, their profit making strategies and the facts that by their activities, they are able to offer employment and training to other people suggest that their entrepreneurial activities contribute to the social and economic development of their communities. The fishmongers have started their businesses out of family circumstances, need for economic development, social status and life changing circumstances suggesting that they are necessity entrepreneurs. However, they could be supported to turn into opportunity entrepreneurs through training and interventions. Based on the above, it is recommended that the fishmongers should be educated on the importance of formal education for their daughters. They should be convinced to encourage their daughters to combine formal education and their traditional system of skill acquisition. This will be of some benefit to them and their businesses. The Ministry of Food and Agriculture as well as other agencies who work with the fishmongers should assist them in acquiring basic numeracy and literacy skills since this will enable them operate their businesses more efficiently. There is also the need for the fishmongers to acquire some business skills such as record keeping, bookkeeping and stock taking to protect themselves and their businesses. This could be done through the Non-formal Education Division or the Integrated Community Centers for Employable Skills (ICCES). The District Assemblies could support and encourage the fishmongers to grow and expand their businesses by providing storage facilities in the various fishing communities.

\section{Reference}

Acs, Z. J., (2007). How Is Entrepreneurship Good for Economic Growth? Innovations, 1(1), 97-107. http://dx.doi.org/10.1162/itgg.2006.1.1.97

Burke A. E., Fitzroy F. R., \& Nolan M. A. (2002). Self-employment wealth and job creation: the roles of gender, non-pecuniary motivation and entrepreneurial ability, Small Business Economics, 19(3), 255-270. http://dx.doi.org/10.1023/A:1019698607772

Buttner, E. H., \& Moore, D. P. (1997). Women's organizational exodus to entrepreneurship: Self-reported motivations and correlates with success. Journal of small business management, 35(1), 34-36.

Coquery-Vidrovitch, C. (1997). African women: A modern history. Boulder, CO: Westview Press.

Ghana Statistical Service (2012). 2010 Population \& Housing Census. Summary Report of Final Results. Ghana Statistical Service, Accra.

Global Entrepreneurship Monitor (GEM), 2003. Worldwide, One in 11 Women Involved in Entrepreneurial Activity - NWBC Analysis Summarizes Global Entrepreneurship Monitor Findings. Washington, DC.

Hall, Chris (2003): Fostering Entrepreneurship and Firm Creation as a Driver of Growth in a 


\section{Macrothink}

Business and Economic Research ISSN 2162-4860 2014, Vol. 4, No. 1

Global Economy, Background paper commissioned by OECD for the Budapest Workshop on "Entrepreneurship in a Global Economy: Strategic Issues and Policies", 8-10 September, Budapest, Hungary.

Hofstede, G. (1991). Cultures and Organizations, London: Harper Collins Publishers.

IFC (2007).Voices of Women Entrepreneurs in Ghana. A report prepared by the IFC/World Bank Investment Climate Team for Africa in collaboration with IFC Gender Entrepreneurship Markets (GEM). Johannesburg, South Africa.

ILO (2006). Vulnerability and Young Women Entrepreneurs: A case study of Ethiopian Informal Economy. Geneva: International Labor Organization.

Jalbert, S. E. (2000). Women Enterprise in the Economy. Washington, DC: Centre for International Private Enterprise.

Minniti, M \&Arenuis, P. (2003).Women in Entrepreneurship: The Entrepreneurial Advantage of Nations. First Annual Global Entrepreneurship Symposium at United Nations Headquarters, April 29, 2003

OECD (1998).Women Entrepreneurs in Small and Medium Enterprises, Proceedings of OECD Conference 1997, Paris.

OECD (2002). Employment Outlook. OECD, Paris.

OECD (2004).Women's Entrepreneurship: Issues and Policies (SMEs). OECD, Paris.

Reynolds, P. D., Hay, M., Camp, M. S., \& Autio, E. (2002).Global Entrepreneurship Monitor: Executive Report. Kauffman Centre for Entrepreneurial Leadership, Kansas City, MO.

Richardson, P. Howarth, R., \& Finnegan (2004). The Challenges of Growing Small Businesses: Insights from Women Entrepreneurs in Africa, SEED Working Paper No. 47

Spring, A. (2009).Empowering women in the African entrepreneurial landscape. In M. Ndulo (Ed.) Power, gender, and social change in Africa and the African Diaspora. Newcastle upon Tyne: Cambridge Scholars.

Stigter, H. W. (1999). VrouwelijkOndernemerschap in Nederland 1994-1997, Zoetermeer: EIM.

THP (2013).Ghana Country Report to the Global Board. The Hunger Project. Retrieved December 17, 2013.

Van Uxem, F. W., \& J. Bais (1996). Het starten van eenbedrijf: ervaringen van 2000 Starters, Zoetermeer: EIM.

Verheul, I., \& Thurik, R. (2001). Start-Up Capital: Does Gender Matter? Small Business Economics, 16(4), 329-45. http://dx.doi.org/10.1023/A:1011178629240

Zewde \& Associates (2002), Jobs, Gender and Small Enterprises in Africa: Women Entrepreneurs in Ethiopia. A Preliminary Report, Geneva: ILO, IFP/SEED-WEDGE 


\section{Copyright Disclaimer}

Copyright reserved by the author(s).

This article is an open-access article distributed under the terms and conditions of the Creative Commons Attribution license (http://creativecommons.org/licenses/by/3.0/). 